\title{
Comparative Study of the Performance of Acetylated Bamboo with Different Catalysts
}

\begin{abstract}
Saisai Huang, Zhongqing Ma,* Yujing Nie,* Fengzhu Lu, and Lingfei Ma *
The catalytic acetylation of bamboo (Phyllostachys pubescens) was compared with acetylation using concentrated sulfuric acid, acetic acid, potassium acetate, and noncatalytic acetylation at $120^{\circ} \mathrm{C}$ for $3 \mathrm{~h}$. The weight percentage gain, dimensional stability, color difference, and wettability of bamboo after the acetylation was comprehensively measured. Also, the chemical and thermal properties of the resultant bamboo were characterized by Fourier transform infrared spectroscopy (FTIR) and thermogravimetric (TG) analysis. The results showed that the potassium acetate-catalyzed acetylation of bamboo greatly accelerated the reaction degree, had little effect on color change, extraordinarily decreased wettability, and had little irregular impact on the dimensional stability. The catalytic activity was followed by potassium acetate, sulfuric acid, noncatalytic acid, and acetic acid. The FTIR analysis showed that the functional groups in the acetylated bamboo were mainly affected by different catalysts. The thermal stability of acetylated bamboo was higher than the untreated bamboo. In particular, potassium acetate-catalytic acetylation greatly reacted with $-\mathrm{OH}$ groups and increased thermal decomposition.
\end{abstract}

Keywords: Bamboo; Acetylation; Catalyst; Dimensional stability; Color; Wettability

Contact information: School of Engineering, Zhejiang Provincial Collaborative Innovation Center for Bamboo Resources and High-Efficiency Utilization, Zhejiang A \& F University, Lin'an district, Hangzhou City, 311300 Zhejiang Province, China;

*Corresponding authors: mazq@zafu.edu.cn; nieyujing@zafu.edu.cn; malingfei@zafu.edu.cn

\section{INTRODUCTION}

With the implementation of natural forest protection policy, the application of bamboo has become an important way to fill the gap between wood supply and demand (Chen et al. 2018a; Zhang et al. 2018). Compared to woody material, bamboo has the advantage of a shorter growth period after harvesting, stronger physical and mechanical properties in the longitudinal direction, and higher rigidity and wear resistance. Therefore, bamboo has been widely used for household utilities, as a composite material, decoration material, or temporary construction material. However, bamboo material suffers from poor dimensional stability and is susceptible to fungi and insects because of the abundant free hydroxyl groups in the cellulose and hemicellulose of bamboo (Ma and Ma 1997; Yang et al. 2008; Chen et al. 2018b). Currently, several methods are being carried out to improve the dimensional stability of bamboo, including mechanical, physical, and chemical methods. By the chemical method, several chemicals have been used, such as anhydrides, acid chlorides, ketene carboxylic acids, isocyanates, formaldehyde, acetaldehyde, and epoxides (Tarkow et al. 1950; Karlson and Svalbe 1977; Rowell 1975; 1982; Kumar 1994; Hon 1996; Hill et al. 2000; Hill 2007). 
Acetylation treatment has the advantage of hypotoxicity, a fast reaction rate, and a simple reaction system, such that it has proven to be one of the most important chemical methods. During the process of acetylation treatment, the hydroxyl groups are converted into acetyl groups by the esterification reaction, which results in lower equilibrium water content and significantly improved dimensional stability (Ohkoshi and Kato 1997). Brelid et al. (2000) reported that acetylation using a limited amount of acetic anhydride in a liquid phase could greatly improve resistance to tunneling bacteria and decay fungi. Furthermore, Ohkoshi (2002) stated that the color of acetylated softwood changed less than that of the untreated softwood after up to $1000 \mathrm{~h}$ of exposure to light. Although these previous studies obviously improved the dimensional stability and resistance to biodegradation, the conventional acetylation treatment had some problems with the accessibility of the reagent to the cell wall, which would greatly decrease the reaction rate of acetylation. Meanwhile, a series of complicated separation procedures to recover the chemicals was required after acetylation treatment (Li et al. 2007). Therefore, a certain extent of modification of acetylation, such as the addition of catalysts, is essential.

Rowell (2006) reported that the most commonly used catalysts in the acetylation treatment were weakly alkaline chemicals or neutral chemicals. Because these series of chemicals could promote the swelling efficiency of the cell wall matrix structure, the reagents to form more acetyl groups could be penetrated in the cell wall. Former studies compared the performance of the acetylation wood by different catalysts, such as zinc chloride, potassium acetate, sodium acetate, acetic acid, magnesium persulfate, and trifluoroacetic acid. Obataya and Minato (2008) indicated that the potassium acetatecatalyzed acetylation of wood could significantly improve the reaction rate with minimal influence on the mechanical properties. Yang et al. (2008) showed the acetylated bamboo pulp, catalyzed by sulfuric acid and a solvent with acetic acid, had higher acetylation activity at a low temperature. Li et al. (2009) stated that the acetylation of wood catalyzed by magnesium chloride showed very little or no effect on the color change or the mechanical properties of the wood. Based on the review of the above references, relatively little information was found to compare the performance of acetylated bamboo with the catalyst of sulfuric acid, acetic acid, and potassium acetate.

The key objective of this work was to investigate the difference in performance of the acetylated bamboo with three types of catalyst, i.e., concentrated sulfuric acid, glacial acetic acid, and potassium acetate. The weight percent gain, dimension stability, color and wettability, functional groups, and thermal properties of acetylated bamboo were tested.

\section{EXPERIMENTAL}

\section{Materials}

Bamboo was collected in the mountains of the Lin'an district, Hangzhou, Zhejiang province, China. The bamboo was cut into chips of certain dimensions, and the outer and inner skin of bamboo was removed. The sizes of bamboo chips were mainly divided into two sets: one set with dimensions of $50 \mathrm{~mm} \times 20 \mathrm{~mm} \times 5 \mathrm{~mm}(\mathrm{~L} \times \mathrm{R} \times \mathrm{T})$ for the color change and wettability tests, and another set with dimensions of $20 \mathrm{~mm} \times 20$ $\mathrm{mm} \times 5 \mathrm{~mm}(\mathrm{~L} \times \mathrm{R} \times \mathrm{T})$ for the dimensional stability testing. Each set had 6 replicates for the test. 
The chemicals used in this experiment were analytically pure. Acetic anhydride $\left[\left(\mathrm{CH}_{3} \mathrm{CO}\right)_{2} \mathrm{O}\right]$ was bought from the Yonghua Chemical Reagent Plant (Jiangsu, China), concentrated sulfuric acid $\left[\mathrm{H}_{2} \mathrm{SO}_{4}\right]$ and potassium acetate $\left[\mathrm{CH}_{3} \mathrm{COOK}\right]$ were bought from the Sinopharm Chemical Reagent Plant (Shanghai, China), and glacial acetic acid $\left[\mathrm{CH}_{3} \mathrm{COOH}\right]$ was bought from the Tianjin Yongda Chemical Regent Company (Tianjin, China).

\section{Experiment of bamboo acetylation}

Bamboo acetylation was performed in a vacuum container. The schematic diagram of this container is shown in Fig. 1. This container was made of stainless steel. The rated capacity, pressure, and temperature was $50 \mathrm{~L}, 1.5 \mathrm{MPa}$, and $220{ }^{\circ} \mathrm{C}$, respectively.

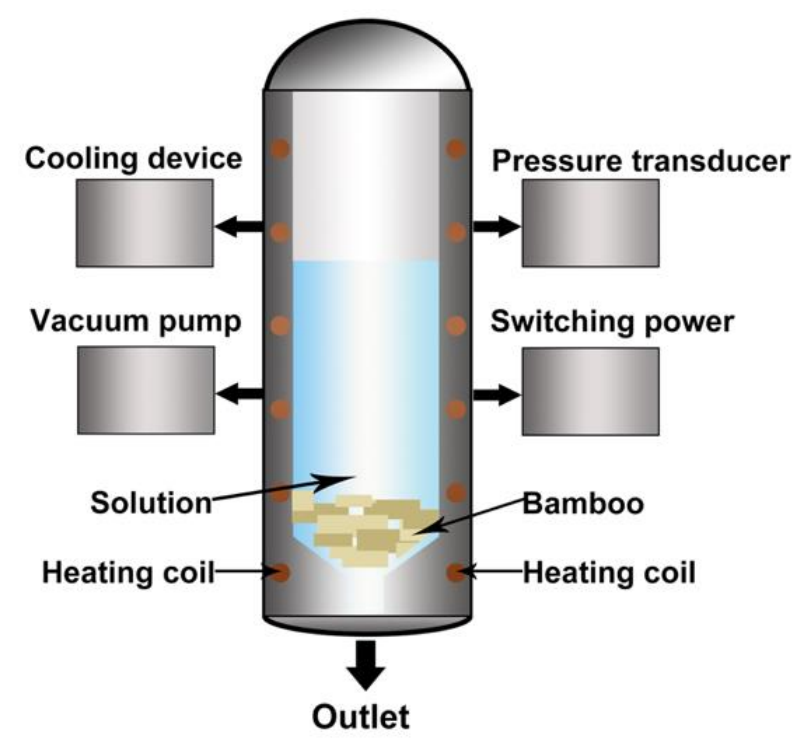

Fig. 1. Schematic of vacuum container for bamboo acetylation

The experimental scheme of bamboo acetylation using different catalysts is shown in Fig. 2. This experiment was divided into five groups, and twelve samples were used in each group. Each experiment was done three times. Before acetylated treatment, each sample was oven-dried at $105{ }^{\circ} \mathrm{C}$ for $5 \mathrm{~h}$. The control sample (CN groups) was oven-dried at $105{ }^{\circ} \mathrm{C}$ for $5 \mathrm{~h}$ without any acetylated treatment.

For the sulfuric acid as a catalyst (SA groups), the samples were first vacuumed at $0.098 \mathrm{MPa}$ for $30 \mathrm{~min}$ in the container. Then, a limited amount of glacial acetic acid was added into the container at room temperature and kept for $2 \mathrm{~h}$ under atmosphere pressure. Next, the acetic acid was removed at the outlet from the bottom of the container. Afterwards, a solution containing acetic anhydride (98 parts) and concentrated sulfuric acid ( 2 parts) was added into the container. Then, the container was heated to $120{ }^{\circ} \mathrm{C}$ under atmosphere pressure and kept for $3 \mathrm{~h}$.

For the acetic acid as a catalyst (AA groups), the samples were first vacuumed for $30 \min (\mathrm{ca} .0 .098 \mathrm{MPa})$ in the container. Then, the samples were soaked in a solution that contained $7 \mathrm{wt} \%$ acetic acid and $93 \mathrm{wt} \%$ acetic anhydride for $2 \mathrm{~h}$ under atmosphere pressure. Next, the container was heated to $120^{\circ} \mathrm{C}$ and held for $3 \mathrm{~h}$. 
For potassium acetate as a catalyst (PA groups), these bamboo chips were primarily soaked in the solution of $15 \mathrm{wt} \%$ potassium acetate (KAc) under atmosphere pressure for $12 \mathrm{~h}$, then air-dried for another $12 \mathrm{~h}$. After being oven-dried for $5 \mathrm{~h}$, these samples were placed into the container and vacuumed for $30 \mathrm{~min}$ (ca. $0.098 \mathrm{MPa}$ ). Then, the acetic anhydride was introduced to the container, and the bamboo samples were submersed for $2 \mathrm{~h}$ at room temperature. Afterwards, the container was heated to $120{ }^{\circ} \mathrm{C}$ and kept for $3 \mathrm{~h}$.

For the no catalyst (NC groups), these samples were first immersed into acetic anhydride under vacuum conditions ( $c a .0 .098 \mathrm{MPa}$ ) for $30 \mathrm{~min}$. In the next phrase, the bamboo samples were soaked in acetic anhydride under atmosphere pressure for $2 \mathrm{~h}$. After that, the container was heated to $120^{\circ} \mathrm{C}$ and kept for $3 \mathrm{~h}$.

After acetylation, the cooling device was turned on, and the container was cooled to $50{ }^{\circ} \mathrm{C}$. The acetylated bamboo specimens were leached with running water for $24 \mathrm{~h}$ to remove the unreacted acetic anhydride or by-product as acetic acid. Then, the acetylated bamboo was vacuum-dried at $0.098 \mathrm{MPa}$ until constant weight was achieved. The drying method was $60{ }^{\circ} \mathrm{C}$ for $48 \mathrm{~h}, 80^{\circ} \mathrm{C}$ for $72 \mathrm{~h}$, and $105^{\circ} \mathrm{C}$ for $48 \mathrm{~h}(\mathrm{Wu}$ et al. 2018).

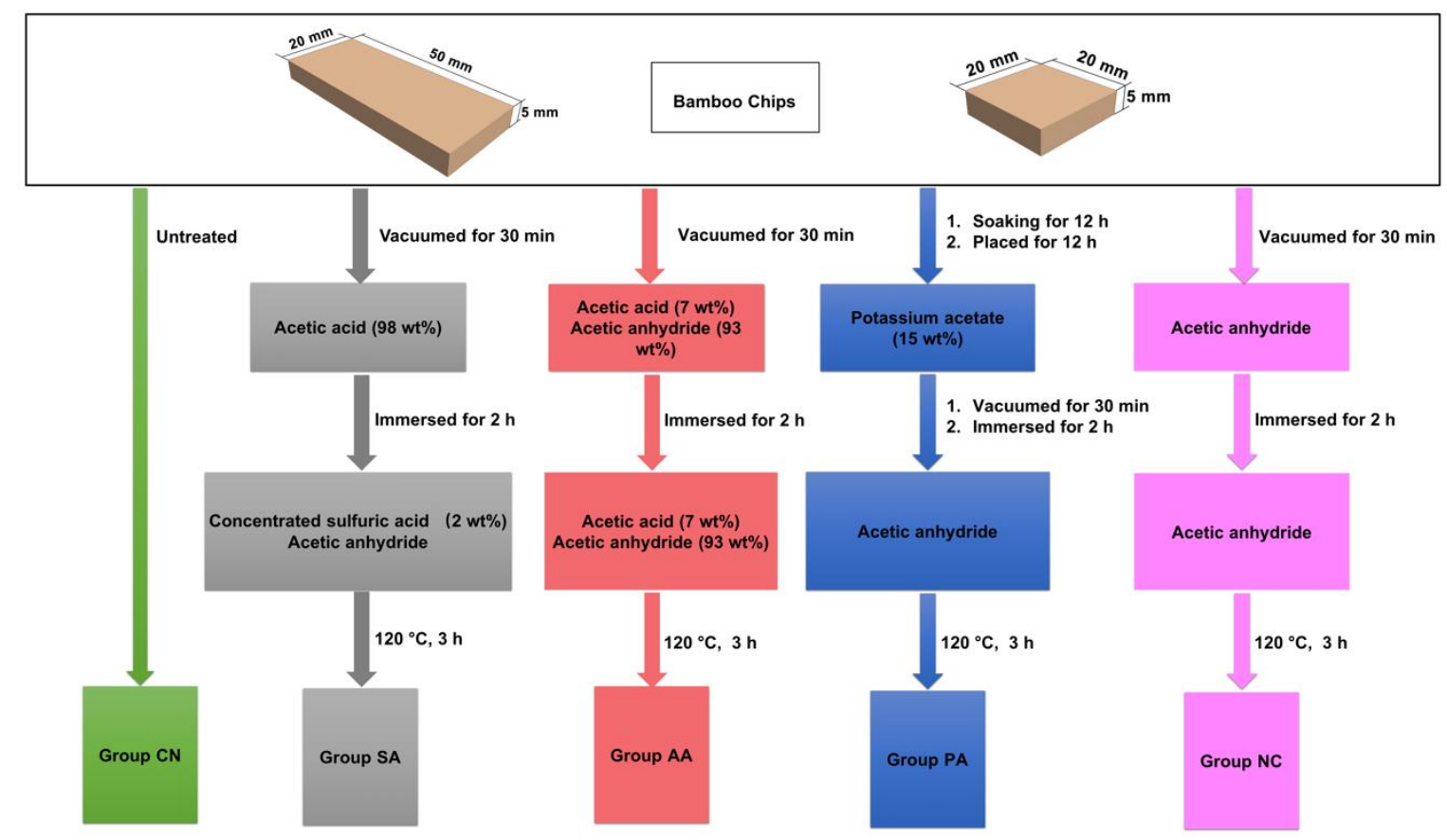

Fig. 2. Experimental scheme of bamboo acetylation using different catalysts

\section{Evaluation of Catalytic Acetylated Bamboo}

Weight percentage gain

Prior to the experiments, both the treated and untreated bamboo samples were dried at $105{ }^{\circ} \mathrm{C}$ for $5 \mathrm{~h}$ to a constant weight, and then the weight was measured. When all of the chemical treatments were finished, the weights of the acetylated bamboo samples were measured again. The weight percentage gain (WPG) was calculated according to Eq. 1,

$$
W P G(\%)=\left(M_{1}-M_{0}\right) / M_{1} \times 100
$$


where $W P G$ is the rate of weight gain $(\%), M_{0}$ is the initial dry weight of the sample $(\mathrm{g})$, and $M_{1}$ is the weight of treated sample $(\mathrm{g})$.

\section{Dimensional stability}

Dimensional stability of the acetylated bamboo was characterized by water absorption and the volume swelling efficiency. The water absorption and the volume swelling efficiency were evaluated according to Chinese National Standard GB/T 1931 (2009) and GB/T 1934.2 (2009). The samples were first submersed into water at $25^{\circ} \mathrm{C}$ for $72 \mathrm{~h}$, and the increasing rate of volume and weight were calculated. Then, the samples were oven-dried at $60{ }^{\circ} \mathrm{C}$ for $2 \mathrm{~h}, 80{ }^{\circ} \mathrm{C}$ for $2 \mathrm{~h}$, and $103{ }^{\circ} \mathrm{C}$ for $4 \mathrm{~h}$ to a constant weight, and the decreasing rate of volume and weight were obtained. The steps of water-soaking and oven-drying were repeated for three times. The water absorption and the volume swelling rate were calculated using Eqs. 2 and 3,

$$
\begin{aligned}
& \operatorname{WAR}(\%)=\left(W_{n}-W_{i}\right) / W_{\mathrm{i}} \times 100 \\
& \operatorname{VSE}(\%)=\left(V_{n}-V_{i}\right) / V_{i} \times 100
\end{aligned}
$$

where $W A R$ is the water absorption rate $(\%), W_{i}$ is the initial weight of the sample $(\mathrm{g}), W_{n}$ is the weight of the sample after being immersed in water $(\mathrm{g}), V S E$ is the volume swelling efficiency $(\%), V_{i}$ is the original volume of the sample $\left(\mathrm{m}^{3}\right)$, and $V_{\mathrm{n}}$ is the volume of the sample after being immersed $\left(\mathrm{m}^{3}\right)$.

\section{Color measurements}

The lightness, redness, and yellowness of the selected points were measured with a colorimeter (DC-P3 Automatic Color Difference Meter, Beijing Xingguang Color Measuring Instrument Co., Ltd., Beijing, China) before and after acetylation treatment according to the CIELAB color standard system $\left(L^{*}, a^{*}\right.$ and $\left.b^{*}\right)$. The differences in parameters $\Delta L^{*}, \Delta a^{*}, \Delta b^{*}$ and the total color differences $\Delta \mathrm{E}^{*}$ were calculated using Eq. 4,

$$
\Delta E^{*}=\sqrt{\Delta L^{* 2}+\Delta a^{* 2}+\Delta b^{* 2}}
$$

where $\Delta E^{*}$ is the total color difference, $L^{*}$ is the lightness, and $a^{*}$ and $b^{*}$ are the color coordinates under any test condition. The $\Delta$ value represents the differences between the initial and final parameters of the specimens after the modification.

\section{Wettability}

The contact angle $(\theta)$ of bamboo was measured by the drop shape method at $20{ }^{\circ} \mathrm{C}$ in a static drop contact angle and interfacial tension tester (OCA 200, DataPhysics, Filderstadt, Germany). A drop of distilled water $(3 \mathrm{~mL})$ was laid upon a bamboo strip using a micro syringe and photographed by the trendsetting 10-fold zoom lens and the high-performance camera with USB 3.0 interface. The contact angle of the droplet with the solid surface was recorded at $0.5 \mathrm{~s}$. At least 10 measurements were made at different inner skin and outer cuticle positions on each group of bamboo specimens.

\section{Fourier transform infrared spectroscopy (FTIR) analysis}

The FTIR spectra of the sample were tested by a Nicolet 6700 (Shimadzu Corporation, Kyoto, Japan) spectrometer. First the modified and untreated bamboo specimens were ground into powder separately and passed through a 200 -mesh screen. After the samples were oven-dried at $105{ }^{\circ} \mathrm{C}, 32$ scans were accumulated for each 
spectrum at a resolution of $4 \mathrm{~cm}^{-1}$ in the region from $4000 \mathrm{~cm}^{-1}$ to $500 \mathrm{~cm}^{-1}$ using $\mathrm{KBr}$ pellets (1 mg power of samples/100 $\mathrm{mg} \mathrm{KBr}$ ).

\section{Thermogravimetric (TG) analysis}

The thermal stability of bamboo was tested using a Thermogravimetric analyzer (TG-209, NETZSCH, Bavaria, Germany). Approximately $5 \mathrm{mg}$ of bamboo powder was placed in an $\mathrm{Al}_{2} \mathrm{O}_{3}$ crucible. The carrier gas and protective gas were high-purity nitrogen with a flow rate of $20 \mathrm{~mL} / \mathrm{min}$ and $20 \mathrm{~mL} / \mathrm{min}$, respectively. The temperature was set from $30{ }^{\circ} \mathrm{C}$ to $600{ }^{\circ} \mathrm{C}$ with a heating rate of $10{ }^{\circ} \mathrm{C} / \mathrm{min}$.

\section{RESULTS AND DISCUSSION}

Figure 3 shows the differences in the weight percentage gain of acetylated bamboo with different catalysts. The results showed that the PA groups exhibited the highest value of WPG (19.59\%) followed by SA (16.89\%), AA (14.18\%), and NC $(17.44 \%)$. These results indicated that a higher content of acetic anhydride penetrated the bamboo cell walls when the KAc catalyst was used. This result was in line with what was reported by Obataya and Minato (2009). They reported that the reactivity of cellulose was powerfully improved by the presence of KAc, thus effectively accelerating the acetylation of wood. Moreover, water-soluble KAc can be easily introduced into the bamboo cell wall. This process can easily accelerate the penetration of acetic anhydride into fibers.

In the presence of acetic acid dissolved into acetic anhydride, the acetylated bamboo did not experience a remarkable WPG in comparison with the other catalysts. This may have been due to the use of $7 \mathrm{wt} \%$ acetic acid, which, like a solvent, reduced the reaction rate because of dilution of the modifier. It can be explained that acetic acid used in AA group played the role as a solvent to reduce the reaction rate. And less acetic anhydride could be reacted with hydroxyl in the bamboo. This outcome was similar to the findings of Yao (2012), who indicated that the bamboo strips also obtained a 13.6\% WPG by the catalyst of $8 \%$ acetic acid at $130{ }^{\circ} \mathrm{C}$.

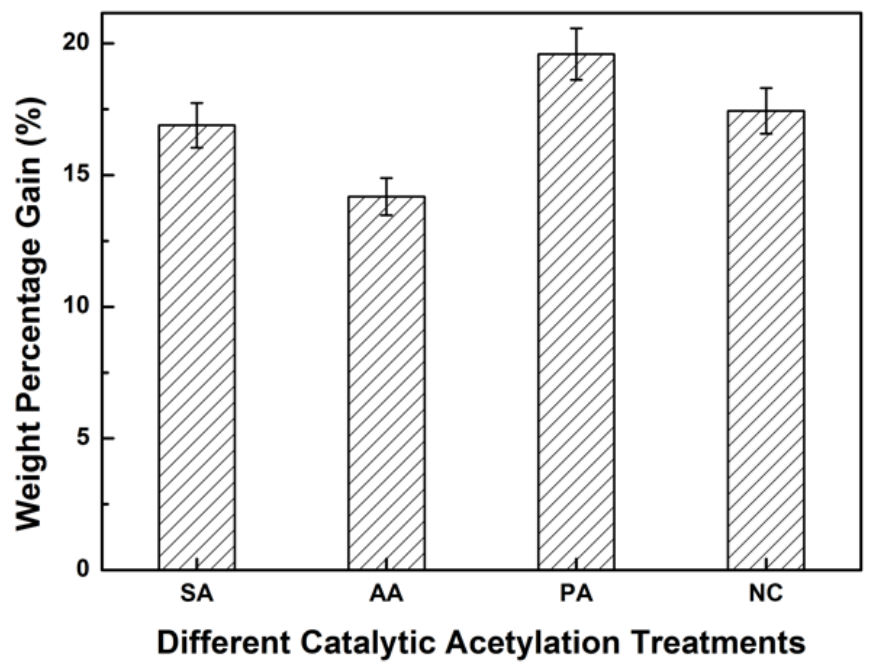

Fig. 3. The weight percentage gain of acetylated bamboo using different catalysts

Huang et al. (2019). "Acetylated bamboo," BioResources 14(1), 44-58. 
Chen et al. (2011) showed that the catalysis of sulfuric acid had greatly activated the hydroxyl groups on the cellulose and lignin, which meant their reaction degree was high. This differs slightly from the findings presented in this study. Here it is reasonable that sulfuric acid used in SA group would deposit on the surface of rayon fibers which retarded the penetration of acetic anhydride into the fibers. Therefore, this would reduce the reaction rate. In contrast, at $120{ }^{\circ} \mathrm{C}$ without the presence of a catalyst, acetic anhydride reacted with bamboo and showed higher reactivity. Jebrane et al. (2011) indicated that acetylated wood can obtain high WPG without a catalyst. The present study showed a similar result.

\section{Dimensional Stability Analysis}

The dimensional stability of acetylated bamboo was evaluated by the WAR and the VSE. Figure 4 shows the water absorption rate and the volume swelling efficiency under different catalysts. The results showed that the acetylated bamboo (SA, AA, PA, and NC) had a higher water resistance capacity and lower VSE than the untreated bamboo $(\mathrm{CN})$. The results revealed that the acetylation treatment decreased the hydrophilicity in bamboo as the number of hydroxyl groups were reduced and the acetyl groups in bamboo were inflated (Rowell 1975).

(a)

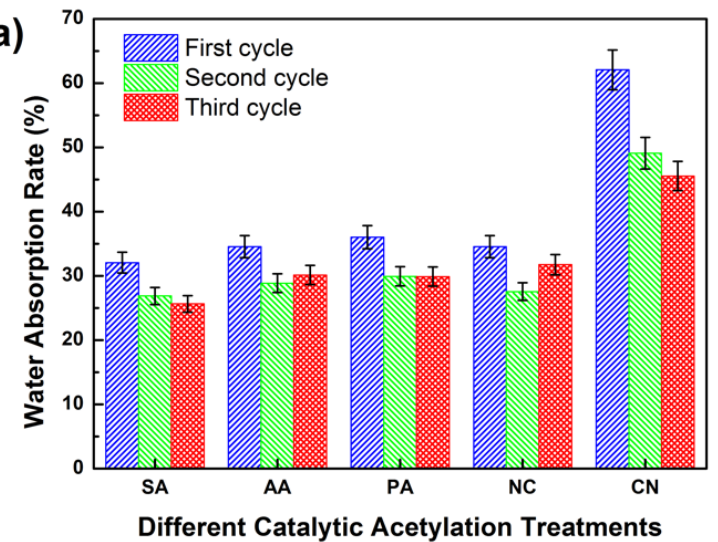

(b)

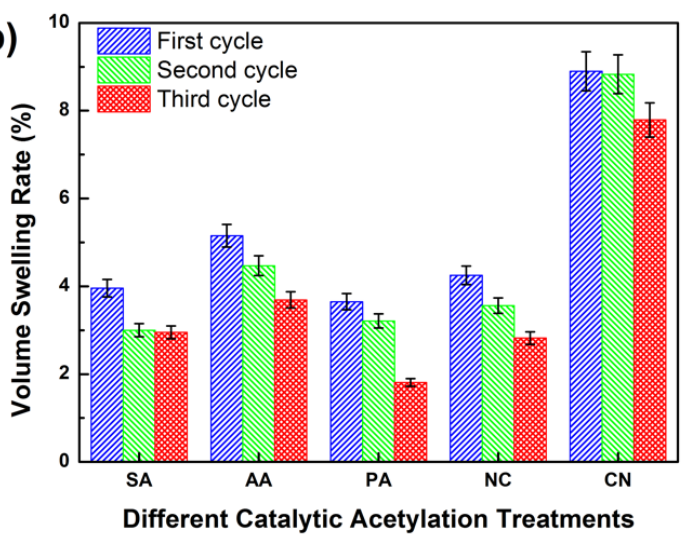

Fig. 4. The WAR (a) and the VSE (b) of control sample and acetylated bamboo using different catalysts

As shown in the Fig. 3, the WPG values of different acetylated bamboo were PA $(19.6 \pm 1 \%, \mathrm{P}<0.05), \mathrm{NC}(17.4 \pm 2 \%, \mathrm{P}<0.05), \mathrm{SA}(16.9 \pm 2 \%, \mathrm{P}<0.05), \mathrm{AA}(14.2 \pm$ $3 \%, \mathrm{P}<0.05)$, respectively. No remarkable difference was observed in the WAR among the three different catalysts. Although the KAc-catalyzed acetylation of bamboo had the highest WPG, its WAR value was the lowest. This suggested that KAc had a negligible effect on the water absorption of the acetylated bamboo. This finding was consistent with that of Obataya and Minato (2008), who stated the effects of uncatalyzed and KAccatalyzed acetylation were not significantly different at the same WPG value.

However, it was obvious that the KAc-catalyzed specimens had a slightly lower VSE value compared to the other acetylated specimens. Such partial acetylation may have resulted in easy access to the inner surface of the cell wall for KAc, while the cell wall was bulked by acetyl groups due to the efficiency of the KAc catalyst.

It was apparent that the SA groups exhibited lower WAR and VSE values than other acetylated bamboo (AA and NC). Yang et al. (2008) stated that concentrated 
sulfuric acid showed remarkable activation in cellulose with the solution of glacial acid and thus increased the degree of acetylated substitution. This finding supported the work of Yang et al. (2008). The AA groups showed higher values of WAR and VSE in this work. Previous studies have demonstrated that acetic acid, as a weak acid, was unable to activate hydroxyl groups in the bamboo, which causes low WPG in acetylation. However, the NC group caused irregularly low dimensional stability with high WPG. It has been suggested that acetylated wood, without the use of a catalyst, has a high resistance because of the covalent bonds being formed between wood and anhydride (Li et al. 2000). This did not appear to be the case when compared to other catalytic acetylation.

Through three soaking-drying tests, the values of all groups decreased remarkably after the first sopping because the extractives were solved in water during the sopping process. The second and third tests saw the values of bamboo specimens steadily decline, which might have been related to the breakage of the water sensitive weak bonds and the swelling of unmodified bamboo cell walls. More esterification may have been required to obtain a higher resistance.

\section{Color Analysis}

Figure 5 shows the color variation of acetylated bamboo under different catalysts. The vertical 0 represents the color of the untreated bamboo. Some published studies have indicated that acetylated wood undergoes a slight color change. Compared with the untreated samples, group AA had a slight color change, because the brightness $\left(\Delta L^{*}\right)$ and red index $\left(\Delta a^{*}\right)$ showed little change. The noncatalytic treatment resulted in more dramatic color changes in all of the samples, mainly a noticeable decrease in $\Delta L^{*}$ and a noticeable increase in $\Delta a^{*}$. This showed that NC groups tended to turn darker and redder after treatment. The green index $\left(\Delta b^{*}\right)$ of KAc catalytic bamboo specimens increased the most, which led the treated bamboo to become yellow. Meanwhile, the degree to which $\Delta L^{*}$ decreased was similar to the increase of $\Delta a *$. The sulfuric acid-catalyzed acetylation of bamboo had a decrease in $\Delta L^{*}$ and an increase in $\Delta a^{*}$ and $\Delta b^{*}$, which resulted in an increase in color difference $\left(\Delta E^{*}\right)$.

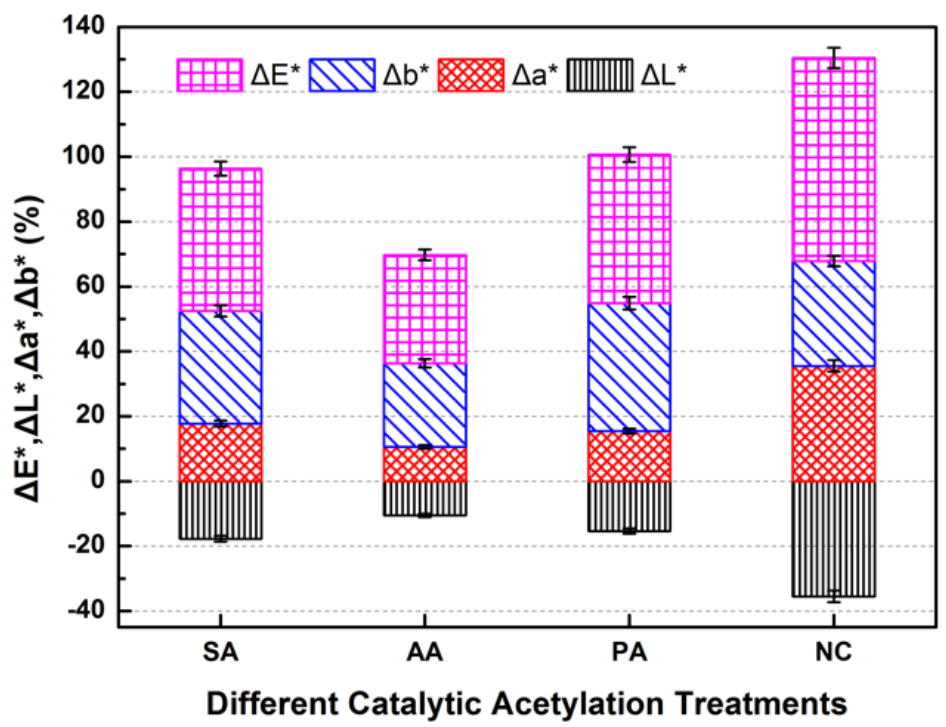

Fig. 5. Color variation $\left(\Delta E^{*}, \Delta L^{*}, \Delta a^{*}\right.$, and $\left.\Delta b^{*}\right)$ of acetylated bamboo using different catalysts 
Chemical modification can cause different degrees of color change of bamboo. According to Ayadi et al. (2003), the color changes were due to an evident change of the major chemical constituents, by means of the decreasing contents of holocellulose and $\alpha$ cellulose and the increasing content of acid-insoluble lignin. Because bamboo has a similar composition to wood, lignin is the main influencing factor for the different colors of bamboo. During the treatment, the main components of the bamboo cell wall were degraded, which resulted in the oxidation of terpenoids, especially the degradation of pentosane in hemicellulose and the content of phenols in the extracts.

\section{Wettability Analysis}

The degree of wetting was evaluated from the contact angle, where larger contact angles correspond to greater hydrophobicity. Figure 6 displays the contact angle of both in the inner and outer surfaces of control and treated samples. The contact angles of all the acetylated bamboo samples were larger than the untreated ones. Interestingly, the contact angles of the KAc-catalytic acetylation of bamboo samples were $101.3^{\circ}$ for the outer and $88.7^{\circ}$ for the inner angle, the highest in the figure. This result suggested that KAc can easily access the cell walls of bamboo, so that the acetic anhydride could ester with hydroxyl groups completely. However, bamboo modified by acetic acid presented a lower contact angle $\left(76.9^{\circ}\right.$ for the outer surface, $67.9^{\circ}$ for the inner surface). For group SA, the contact angles of the outer and inner surfaces were $96.6^{\circ}$ and $72.4^{\circ}$, respectively. In addition, the contact angles of group $\mathrm{NC}$ were $80.8^{\circ}$ and $72.2^{\circ}$. The contact angle of the untreated samples for the outer and inner surfaces were $58.8^{\circ}$ and $51.5^{\circ}$, respectively. It was shown that the untreated bamboo contained a large number of hydroxyl groups, making it more polar and more hydrophilic; via acetylation, a large number of hydroxyl groups were replaced by acetyl groups to form ester groups, reducing the number of hydrophilic groups (Çetin et al. 2011). Therefore, to obtain great wettability of acetylated bamboo, more acetic anhydride should be reacted.

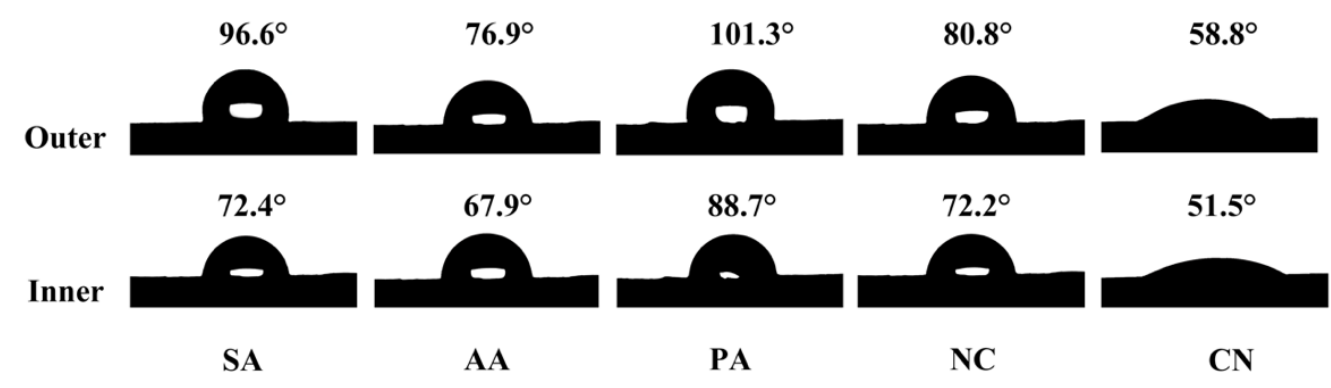

Fig. 6. The contact angle of control sample and acetylated bamboo using different catalysts

\section{FTIR Analysis}

The FTIR analysis of the acetylated bamboo samples with different catalysts and control sample is illustrated in Fig. 7. The $\mathrm{CN}$ curve corresponded to the IR spectrum of untreated bamboo. The NC, PA, AA, and SA curves represented the acetylated bamboo in different catalytic conditions. The infrared spectra between the control sample and acetylated bamboo specimens were shown to be quite similar. The characteristic absorption of the grafted acetyl groups was associated with $1740 \mathrm{~cm}^{-1}, 1377 \mathrm{~cm}^{-1}$, and $1220 \mathrm{~cm}^{-1}$. Another noticeable difference observed in the spectra was the reduced intensities of the bonds at $3400 \mathrm{~cm}^{-1}$ and $2930 \mathrm{~cm}^{-1}$. 
In the acetylated specimens, the peaks at $3400 \mathrm{~cm}^{-1}$ and $2930 \mathrm{~cm}^{-1}$ were assigned to the $-\mathrm{OH}$ groups and $\mathrm{CH}_{2}$ groups of cellulose, hemicellulose, and lignin. Meanwhile, these bending peaks became gradually weaker in different catalytic treatments compared to the control bamboo, i.e., $\mathrm{CN}<\mathrm{AA}<\mathrm{SA}<\mathrm{NC}<\mathrm{PA}$. This inconsistency may have been due to the bamboo components undergoing hydrogen bond cleavage after treatment with acetic anhydride, which caused the hydrogen atom on the hydroxyl groups to be replaced by an acetyl group. This finding was also reported by Rowell (1975), Ohkoshi (2002), Jebrane et al. (2011), and Chai et al. (2016). The decrease of -OH groups and $\mathrm{CH}_{2}$ groups in the order $\mathrm{CN}<\mathrm{AA}<\mathrm{SA}<\mathrm{NC}<\mathrm{PA}$ may have resulted in the different WPG values gained from different catalytic conditions. Among the three catalysts, KAc catalytic bamboo mostly reacted with acetic anhydride, which indicated that more - $\mathrm{OH}$ groups were replaced at higher acetylation degrees. Because the $-\mathrm{OH}$ groups and $\mathrm{CH}_{2}$ groups are abundant in cellulose, hemicellulose, and lignin, it can therefore be assumed that the cellulose, hemicellulose, and lignin could all participate in the acetylation reaction. This also accorded with the report from Chai et al. (2016). Moreover, the -OH groups were highly hydrophilic, and the acetylation reduced the number of -OH groups in bamboo. This corresponded with the improvement in the dimensional stability of acetylated bamboo.

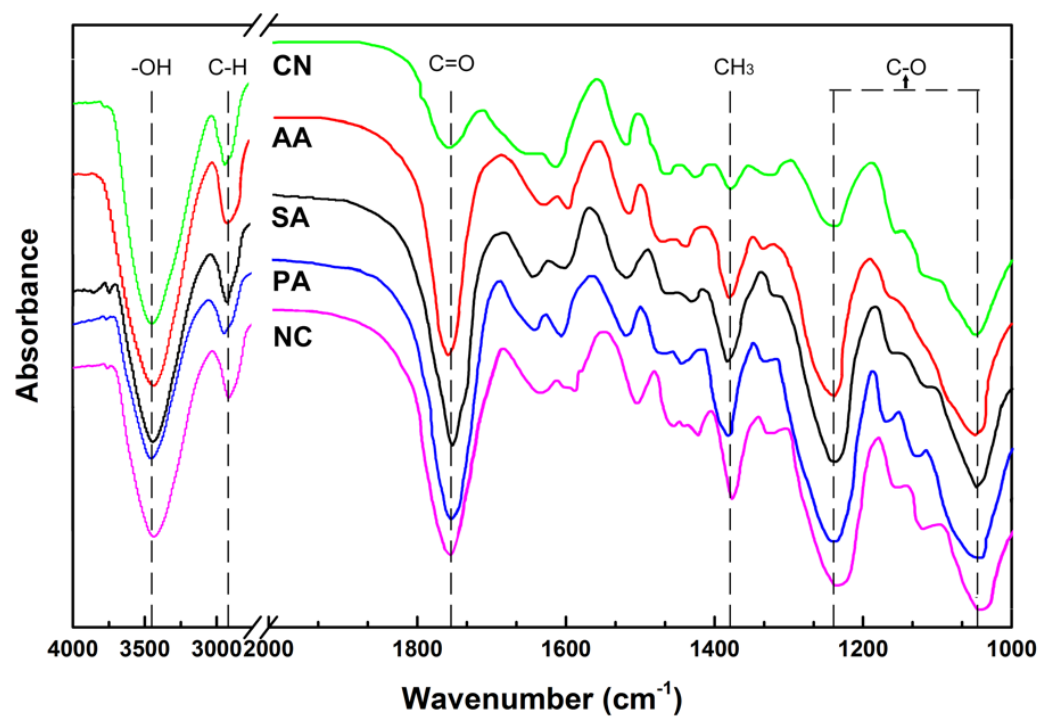

Fig. 7. The FTIR analysis of control sample and acetylated bamboo using different catalysts

The absorption intensity of the bands located at $1740 \mathrm{~cm}^{-1}$ was attributed to the acetyl group $\mathrm{C}=\mathrm{O}$ of xylan of hemicellulose. The remarkable increase of the intensity of $\mathrm{C}=\mathrm{O}$ indicated that bamboo successfully acetylated with reagent. This result was also confirmed in Fig. 3. Group PA had a relatively high value of WPG, resulting in more acetyl groups reacting with the hydroxyl groups. According to Yang et al. (2008), cellulose and hemicellulose can by converted by acetylation treatment. This indicated that the crystallinity of acetylated bamboo was reduced, causing cleavage of the glyosidic bond and decreasing the degree of polymerization. Therefore, more acetic anhydride was linked on the surface of bamboo. The appearance of the peak at $1740 \mathrm{~cm}^{-1}$ varied as $\mathrm{CN}<$ $\mathrm{AA}<\mathrm{SA}<\mathrm{NC}<\mathrm{PA}$, which suggested that a higher WPG value could increase the overlap with carbonyl in acetyl groups. It was found that hemicellulose was an 
amorphous substance with a branchy structure, and the main chain or the side chain contained hydrophilic groups, which are the most hygroscopic component in bamboo (Cai et al. 2013). Hence, the hydrophilic groups were substituted by the hydrophobic groups after acetylation, which had an important effect in reducing the hygroscopicity of bamboo. The results of this work have significance for further research. Compared with the untreated bamboo specimens, the frequency bands at $1377 \mathrm{~cm}^{-1}$ and $1220 \mathrm{~cm}^{-1}$ showed great peaks in the acetylated samples, which can be attributed to the $-\mathrm{CH}_{3}$ bending vibration and the $\mathrm{C}-\mathrm{O}$ bending vibration, respectively (Ma et al. 2015). The results in Fig. 3 show that the KAc catalytic acetylation was the better activation method due to its higher acetylation degree. The results were in line with those inferred from Fig. 8.

\section{TG Analysis}

Figure 8 depicts the TG (a) and DTG (b) thermograms of untreated and treated bamboo samples to observe the thermal degradation behavior. As shown in Fig. 8, the curves of the modified samples and control samples were quite similar. It can be seen from the TG curves, the residual mass of acetylated sample was higher than the control sample. From the DTG curves, although the temperature at the point of maximum weight loss for the acetylated sample was higher than the control sample, the maximum weight loss of acetylated sample was higher than the control sample. Therefore, the thermal stability of acetylated bamboo was much higher than the untreated bamboo. These results agree with some of earlier findings in acetylated wood (Yang et al. 2008; Nagarajappa and Pandey 2016). A three-stage weight loss of bamboo samples was observed from the DTG curves (Antal and Varhegyi 1995; Ma et al. 2016).

(a)

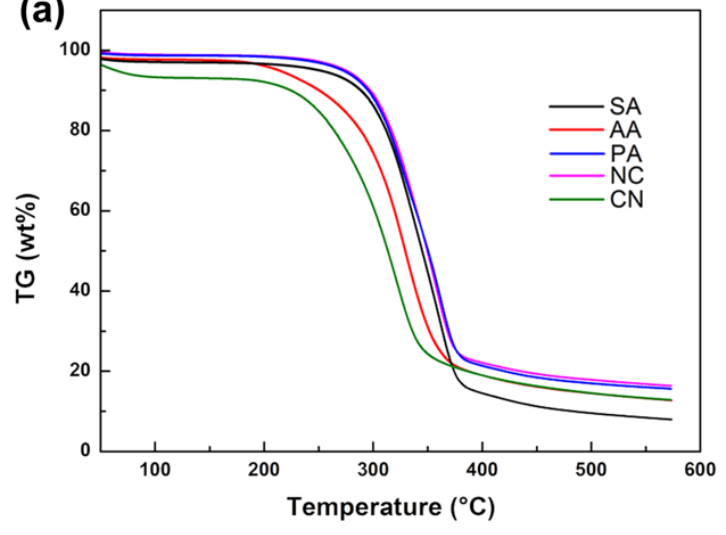

(b)

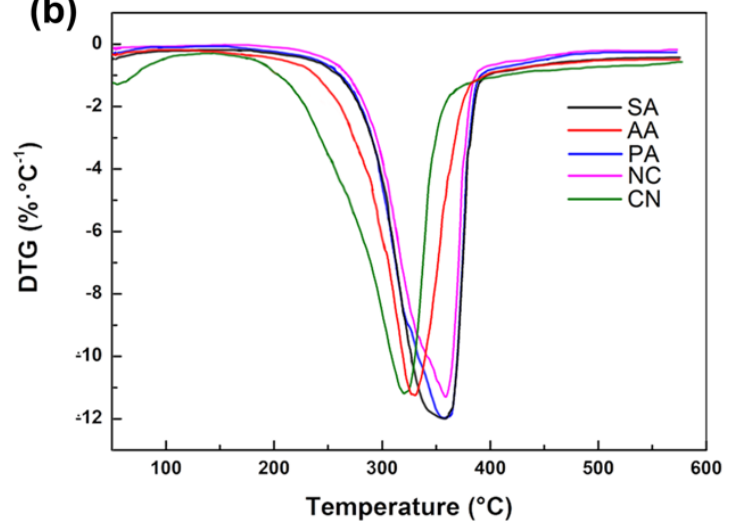

Fig. 8. The TG (a) and DTG (b) curves of control sample and acetylated bamboo using different catalytic at a heating rate of $10 \mathrm{~K} / \mathrm{min}$

The first stage was below $220{ }^{\circ} \mathrm{C}$, in which the weight loss was less, mainly due to the evaporation of water in the bamboo, and the chemical composition of the bamboo did not change obviously. It can be seen from the TG curve (a) that the pre-pyrolysis phase of the acetylated bamboo samples lasted for a longer time than the control samples. The acetylated bamboo started to be greatly pyrolyzed when it was heated to approximately $300{ }^{\circ} \mathrm{C}$, with a smaller mass loss. This result indicated that the acetylation treatment effectively improved the thermal tolerance of the bamboo samples. There were 
similarities between the attitudes expressed by $\mathrm{Li}$ et al. (2009). The first temperature range of different catalysts was PA $\left(30{ }^{\circ} \mathrm{C}\right.$ to $\left.303{ }^{\circ} \mathrm{C}\right), \mathrm{NC}\left(30^{\circ} \mathrm{C}\right.$ to $\left.300{ }^{\circ} \mathrm{C}\right)$, SA $\left(30{ }^{\circ} \mathrm{C}\right.$ to $\left.299{ }^{\circ} \mathrm{C}\right)$, AA $\left(30{ }^{\circ} \mathrm{C}\right.$ to $283{ }^{\circ} \mathrm{C}$ ), and $\mathrm{CN}\left(30{ }^{\circ} \mathrm{C}\right.$ to $\left.265^{\circ} \mathrm{C}\right)$. In particular, the first temperature range of acetic acid catalytic bamboo was similar to that of the control samples, because it had the lowest weight gain. However, the starting point of KAc catalytic bamboo pyrolysis was approximately $303{ }^{\circ} \mathrm{C}$, which indicated that a higher WPG of the acetylated bamboo had a higher degree of heat resistant solution. This finding confirmed that the KAc could greatly accelerate the acetylation rate.

The second stage of the control samples was approximately $220{ }^{\circ} \mathrm{C}$ to $390{ }^{\circ} \mathrm{C}$. At this stage, intense destruction of the crystalline region and the simultaneous decomposition of the polymer occurred. Thus, the amorphous structure increased, while the degree of polymerization decreased. According to the DTG curve, the second stage could be divided to two parts, one for $220{ }^{\circ} \mathrm{C}$ to $320{ }^{\circ} \mathrm{C}$, and another one for $320{ }^{\circ} \mathrm{C}$ to $390{ }^{\circ} \mathrm{C}$, respectively. Unstable components, such as hemicellulose, were thermally decomposed into $\mathrm{CO}_{2}, \mathrm{CO}, \mathrm{H}_{2} \mathrm{O}$, or another gas during the first part (Ma et al. 2018a). When the temperature increased to $375{ }^{\circ} \mathrm{C}$, the weight loss rate was nearly $78 \%$, accompanied by a large amount of thermal decomposition products from the cellulose molecular chain, lignin, and the remaining hemicellulose, i.e., methane, ethylene, acetic acid, or tar (Yang et al. 2008). Meanwhile, the decomposition temperature range of acetylated bamboo was higher than the control samples, which once again showed that the thermal stability of modified bamboo was more stable. The decomposition temperature of different catalytic acetylation was PA $\left(385{ }^{\circ} \mathrm{C}\right)>\mathrm{NC}\left(378{ }^{\circ} \mathrm{C}\right)>\mathrm{SA}$ $\left(350{ }^{\circ} \mathrm{C}\right)>\mathrm{AA}\left(338^{\circ} \mathrm{C}\right)$, which showed that KAc catalytic treatments had noticeable thermal stability. The bamboo samples had an exothermic peak in the range of $250{ }^{\circ} \mathrm{C}$ to $400{ }^{\circ} \mathrm{C}$ on the DTG curve, which was caused by the decomposition of the crystallization zone.

During the third stage $\left(390{ }^{\circ} \mathrm{C}\right.$ to $\left.600{ }^{\circ} \mathrm{C}\right)$, both the control samples and acetylated samples had a slow weight loss rate and the crystalline region had been completely destroyed. The cellulose decomposed into a monomer of $\beta$-D-glucopyranose, and low molecular weight hemicellulose and lignin were degraded (Yang et al. 2008; Ma et al. 2018 b). Nearly $90 \%$ decomposition of the control samples occurred at $390{ }^{\circ} \mathrm{C}$, while decomposition of the acetylated bamboo occurred at $410{ }^{\circ} \mathrm{C}$. This finding broadly supported the work of other studies in this area.

\section{CONCLUSIONS}

1. Potassium acetate (KAc)-catalytic acetylated bamboo specimens obtained the highest weight percentage gain (WPG) (19.6\%) indicating that KAc can greatly enhance acetic anhydride immersion into bamboo cells. As a result of acetylation, all of the bamboo specimens showed improved dimensional stability under the water soakingdrying procedure, while the KAc-catalytic acetylated bamboo specimens had the greatest hydrophobicity.

2. The bamboo specimens became darker after acetylation treatments, while noncatalytic acetylation greatly changed the color among the other three treatments.

3. Acetylation reduced the wettability and increased the contact angle of the bamboo specimens. Another important finding was that KAc-catalytic acetylation greatly 
increased the contact angle of bamboo. In contrast, acetylated bamboo catalyzed by acetic acid slightly increased the contact angle of bamboo.

4. The FTIR spectroscopy revealed that the differences in the functional groups of the acetylated bamboo were mainly affected by different catalysts. The KAc had a remarkable reactivity with regards to bamboo components.

5. The thermal stability of acetylated bamboo was higher than that of the untreated bamboo, while KAc-catalytic acetylated bamboo showed the highest thermal decomposition.

\section{ACKNOWLEDGMENTS}

The authors are grateful for the support from the Public Welfare Technology Application Research Project of Zhejiang Province (LQ14C160002, 2017C37078), the National Natural Science Foundation of China (31270592, 51706207), the National Key R \& D Plan of the "13th Five-Year" (2017YFD0601105), the Natural Science Foundation of Zhejiang Province (LQ17E060002), the Young Elite Scientists Sponsorship Program by CAST (2018QNRC001), and the Fund of Zhejiang Provincial Collaborative Innovation Center for Bamboo Resources and High-Efficiency Utilization (2017ZZY2-02).

\section{REFERENCES CITED}

Antal, M. J. J., and Várhegyi, G. (1995). "Cellulose pyrolysis kinetics: The current state of knowledge," Industrial and Engineering Chemistry Research 34(3), 703-717. DOI: 10.1021/ie00042a001

Ayadi, N., Lejeune, F., Charrier, F., Charrier, B., and Merlin, A. (2003). "Color stability of heat-treated wood during artificial weathering," Holz als Roh-und Werkstoff 61(3), 221-226. DOI: 10.1007/s00107-003-0389-2

Brelid, P. L., Simonson, R., Bergman, Ö., and Nilsson, T. (2000). "Resistance of acetylated wood to biological degradation," Holz als Roh-und Werkstoff 58(5), 331337. DOI: $10.1007 / \mathrm{s} 001070050$

Cai, J., Fei, P., Xiong, Z., Shi, Y., Yan, K., and Xiong, H. (2013). "Surface acetylation of bamboo cellulose: Preparation and rheological properties," Carbohydrate Polymers 92(1), 11-18. DOI: 10.1016/j.carpol.2012.09.059

Çetin, N. S., Özmen, N., and Birinci, E. (2011). "Acetylation of wood with various catalysts," Journal of Wood Chemistry and Technology 31(2), 142-153. DOI: 10.1080/02773813.2010.503981

Chai, Y., Liu, J., Wang, Z., and Zhao, Y. (2016). "Dimensional stability and mechanical properties of plantation poplar wood esterified using acetic anhydride," BioResources 12(1), 912-922. DOI: 10.15376/biores.12.1.912-922

Chen, D. Y., Gao, A. J., Ma, Z. Q., Fei, D. Y., Chang, Y., and Shen, C. (2018a). “Indepth study of rice husk torrefaction: Characterization of solid, liquid and gaseous products, oxygen migration and energy yield," Bioresource Technology 253, 148-153. DOI: 10.1016/j.biortech.2018.01.009 
Chen, D. Y., Gao, A. J., Cen, K. H., Zhang, J., Cao, X. B., and Ma, Z. Q. (2018b). "Investigation of biomass torrefaction based on three major components: Hemicellulose, cellulose, and lignin," Energy Conversion and Management 169, 228237. DOI: 10.1016/j.enconman.2018.05.063

Chen, H., Miao, M., and Ding, X. (2011). "Chemical treatments of bamboo to modify its moisture absorption and adhesion to vinyl ester resin in humid environment," Journal of Composite Materials 45(14), 1533-1542. DOI: 10.1177/0021998310385023

GB/T 1931-2009 (2009). "Method for determination of the moisture content of wood," Standardization Administration of China, Beijing, China. (In Chinese)

GB/T 1934.2-2009 (2009). "Method for determination of the swelling of wood," Standardization Administration of China, Beijing, China. (In Chinese)

Jebrane, M., Pichavant, F., and Sèbe, G. (2011). "A comparative study on the acetylation of wood by reaction with vinyl acetate and acetic anhydride," Carbohydrate Polymers 83(2), 339-345. DOI: 10.1016/j.carbpol.2010.07.035

Hill, C. A. (2007). Wood Modification: Chemical, Thermal and Other Processes, John Wiley \& Sons, Chichester, UK.

Hill, C. A. S., Çetin, N. S., and Ozmen, N. (2000). "Potential catalysts for the acetylation of wood," Holzforschung 54(3), 269-272. DOI: 10.1515/HF.2000.045

Hon, D. N.-S. (1996). Chemical Modification of Wood Materials, Marcel Dekker, New York, NY.

Karlson, I., and Svalbe, K. (1977). "Method of acetylating wood with gaseous ketene," Latv Lauksiamn Akad Raksti 130, 10-21.

Kumar, S. (1994). "Chemical modification of wood," Wood and Fiber Science 26(2), 270-280.

Li, J. Z., Furuno, T., and Katoh, S. (2007). "Wood propionylation in the presence of catalysts," Wood and Fiber Science 33(2), 255-263. DOI: 10.1080/02773810903009499

Li, J. Z., Furuno, T., Zhou, W. R., Ren, Q., Han, X. Z., and Zhao, J. P. (2009). "Properties of acetylated wood prepared at low temperature in the presence of catalysts," Journal of Wood Chemistry and Technology 29(3), 241-250. DOI: 10.1080/02773810903009499

Ma, L., and Ma, N. (1997). "Study on variation in bamboo wood properties of Phyllostachys heterocycla var. pubescens," Forestry Science 33(4), 356-364.

Ma, Z., Chen, D., Gu, J., Bao, B., and Zhang, Q. (2015). "Determination of pyrolysis characteristics and kinetics of palm kernel shell using TGA-FTIR and model-free integral methods," Energy Conversion and Management 89(1), 251-259. DOI: 10.1016/j.enconman.2014.09.074

Ma, Z., Sun, Q., Ye, J., Yao, Q., and Zhao, C. (2016). "Study on the thermal degradation behaviors and kinetics of alkali lignin for production of phenolic-rich bio-oil using TGA-FTIR and Py-GC/MS," Journal of Analytical and Applied Pyrolysis 117, 116124. DOI: 10.1016/j.jaap.2015.12.007

Ma, Z., Wang, J., Yang, Y., Zhang, Y., Zhao, C., Yu, Y., and Wang, S. (2018 a). "Comparison of the thermal degradation behaviors and kinetics of palm oil waste under nitrogen and air atmosphere in TGA-FTIR with a complementary use of modelfree and model-fitting approaches," Journal of Analytical and Applied Pyrolysis134, 12-24. DOI: 10.1016/j.jaap.2018.04.002

Ma, Z. Q., Wang, J. H., Zhou, H. Z., Zhang, Y., Yang, Y. Y., Ye, J. W., Liu, X. H., and Wang, S. R. (2018). "Relationship of thermal degradation behavior and chemical 
structure of lignin isolated from palm kernel shell under different severities," Fuel Processing Technology 181, 142-156. DOI: 10.1016/j.fuproc.2018.09.020

Nagarajappa, G. B., and Pandey, K. K. (2016). "UV resistance and dimensional stability of wood modified with isopropenyl acetate," Journal of Photochemistry and Photobiology B: Biology 155, 20-27. DOI:10.1016/j.jphotobiol.2015.12.012

Obataya, E., and Minato, K. (2008). "Potassium acetate-catalyzed acetylation of wood: Extraordinarily rapid acetylation at $120{ }^{\circ} \mathrm{C}$," Wood Science and Technology 42(7), 567-577. DOI: $10.1007 / \mathrm{s} 00226-008-0179-4$

Obataya, E., and Minato, K. (2009). "Potassium acetate-catalyzed acetylation of wood at low temperatures I: Simplified method using a mixed reagent," Journal of Wood Science 55(1), 18-22. DOI: 10.1007/s10086-008-0995-z

Ohkoshi, M. (2002). "FTIR-PAS study of light-induced changes in the surface of acetylated or polyethylene glycol-impregnated wood," Journal of Wood Science 48(5), 394-401. DOI: 10.1007/BF00770699

Ohkoshi, M., and Kato, A. (1997). "13C-NMR analysis of acetyl groups in acetylated wood II: Acetyl groups in lignin," Journal of the Japan Wood Research Society 43, 364-369.

Rowell, R. M. (1975). "Chemical modifications of wood: Advantages and disadvantages,” in: American Wood-Preservers' Association, Proceedings, Vol. 71, pp. 41-51.

Rowell, R. M. (2006). "Acetylation of wood - Journey from analytical technique to commercial reality," Forest Products Journal 56(9), 4-12.

Wu, H., Yang, X., Rao, J., Zhang, Y., and Sun, F. (2018). "Improvement of bamboo properties via in situ construction of polyhydroxyethyl methylacrylate and polymethyl methylacrylate networks," BioResources 13(1), 6-14. DOI:10.15376/biores.13.1.6-14

Yang, Z., Xu, S., Ma, X., and Wang, S. (2008). "Characterization and acetylation behavior of bamboo pulp," Wood Science and Technology 42(8), 621-632. DOI: 10.1007/s00226-008-0194-5

Yao, W. (2012). Citrogen Acetylation Process and Performance Study, Master's Thesis, Nanjing Forestry University, Nanjing, China. (In Chinese)

Zhang, Y. M., Ma, Z. Q., Zhang, Q. S., Wang, J. Y., Ma, Q. Q., Yang, Y. Y., Luo, X. P., and Zhang, W. G. (2018). "Comparison of the physicochemical characteristics of biochar pyrolyzed from moso bamboo and rice husk with different pyrolysis temperatures," BioResources 13(2), 4652-4669. DOI: 10.15376/biores.12.3.46524669

Article submitted: July 27, 2018; Peer review completed: September 23, 2018; Revised version received: October 11, 2018; Accepted: October 25, 2018; Published: November $5,2018$.

DOI: $10.15376 /$ biores.14.1.44-58 